\title{
Development challenges in challenging contexts: A 3-stage curriculum framework design approach for Education in Emergencies
}

\author{
Martin Johnson $^{1} \cdot$ Sinéad Fitzsimons $^{2} \cdot$ Victoria Coleman $^{3}$
}

Accepted: 2 January 2022

(C) The Author(s) under exclusive licence to UNESCO International Bureau of Education 2022

\begin{abstract}
There is a pressing need to develop processes to facilitate the organization of education responses in time-pressured emergency situations. As part of a joint Learning Passport (LP) partnership project with UNICEF, researchers along with curriculum and subject specialists at the University of Cambridge, UK, developed a curriculum framework that could be used as a resource for coordinating the actions of education specialists and practitioners in Education in Emergencies (EiE) situations. This article outlines the curriculum framework design approach they developed for the Maths and Science components of the LP framework. The article outlines a three-stage curriculum framework development model, which involves consideration of context, leading to descriptor generation, and attending to cohesion building elements.
\end{abstract}

Keywords Curriculum framework - Education in Emergencies · Education design

In this article we outline some of the processes we devised when developing the Maths and Science components of the Learning Passport (LP) curriculum framework (https://

The main author would like to thank his co-authors, who completed their work when they were employed at Cambridge Assessment.

Martin Johnson

martin.johnson@cambridge.org

Sinéad Fitzsimons

fitzsimonss@isb.be

Victoria Coleman

vlc21@bath.ac.uk

1 Research Division, Cambridge University Press \& Assessment, Shaftesbury Road, Cambridge CB2 8EA, UK

2 The International School of Brussels, Kattenberg 19, 1170 Watermael-Boitsfort, Belgium

3 Department of Psychology, University of Bath, Claverton Down, Bath BA2 7AY, UK 
www.learningpassport.org/reports/curriculum-framework-maths-science-literacy). The LP is a joint partnership project involving UNICEF, the University of Cambridge (UK), and Microsoft. A central aspect of the project was developing a curriculum framework that would aim to close the "learning poverty gap" that sees many millions of primary-level children failing to achieve minimum proficiency levels in their education. Although we recognized the important issue of learner disengagement from education at the older age range, for resourcing reasons we decided to focus our framework on the earliest foundational stages of learning. This framework would focus on Maths, Science, Literacy, and Social and Emotional Learning. As researchers, and curriculum and subject specialists, at the University of Cambridge, we were involved in the development of the LP framework.

Prior to outlining our $C D C$ framework development model, we set the context by describing some of the challenges of Education in Emergencies (EiE) contexts. We then outline the three-stage approach we took to developing a curriculum framework for displaced learners. This approach involves establishing a set of principles to guide development, generating learning content descriptors, and then establishing coherence across the framework.

\section{The challenges of Education in Emergency (EiE)}

When emergency contexts arise, they pose a challenge to ensuring education provision. They are characterized by conditions of instability and insecurity, which affect the management of education. At a system level these challenges can include: coordinating the actions of the various agencies at work in an Emergency Education Sector (which may include NGOs, educational charities, state entities, etc.); marshalling the diverse and potentially competing agendas that can characterize multi-agency working (Devitt \& Borodzicz, 2008); dealing with misalignment between the languages of displaced learners and that of a new context (Çelik \& İçduygu, 2019); engaging with resource challenges (e.g., teacher and learning material provision) (Mendenhall et al., 2018); navigating around NGO staffing rotations in education sectors (Green, 2013); working around limitations on available learning time (UNHCR, 2016a); and, perhaps most significantly, dealing with individual uncertainties about what happens next for learners (e.g., where they will go, and what other education they may potentially access once the emergency is over) (Dhillon et al., 2009).

We argue that curriculum framework development can help coordinate educational action and structure a high-quality emergency response. For some, this response should focus on integrating displaced learners into a host country's education system through facilitating access to the host country's curriculum (e.g., UN, 2018, 2019). We also recognize that integrating displaced learners into a host system is not always possible, perhaps due to political sensitivities. Where this is the case it is necessary to devise a framework that can be a foundation for developing specific learning programs and learning materials that will allow those learners to access other systems when it becomes possible for them to do so.

A key benefit of a curriculum framework is that it provides a universal set of underpinning reference points that generalize across a variety of contexts, and therefore affords transfer into and between different education systems. There is a rich heritage of initiatives that use frameworks for coordinating actions. For example, UNHCR draw on a framework approach when mobilizing national and international stakeholders to focus on shared goals (Education Co-Sponsorship Alliance, 2019, p. 4). Looking specifically at learning 
contexts, the OECD acknowledge that frameworks can support partners' shared orientation (OECD, 2018, p. 3). Waters et al. (2018) also highlight how learning progression frameworks allow teachers to monitor learning growth, acknowledging Australia's endorsement of national progression frameworks as a tool for improving teaching and learning (Australian Government, 2018).

In the next section we outline what we mean by a curriculum framework, before describing the three stages that characterize the framework development process.

\section{What is a curriculum framework?}

"Curriculum framework" and "curriculum" are terms that are often used interchangeably, but for us the distinction between the concepts is important. Frameworks have generalizing affordances that make them potentially applicable across a number of situations. This distinguishes frameworks from specific curricula, which cannot be easily transferred across different contexts. For us, a curriculum framework is the foundation reference for the construction of a specific curriculum.

This distinction matches the description outlined by Seifert (2019), who notes that a curriculum framework is a document that explains how content standards can or should be organized for a particular subject and at various grade levels - the scope and sequence for a curriculum.

In our focus on how a framework document can structure subject content and concept sequences rather than provide detailed suggestions for daily teaching, we draw attention to another feature distinguishing frameworks from curricula. Since curriculum frameworks deal with high-level sequencing of learning concepts, they encourage parsimony. This means that a framework does not include the amount of detail that is required of programs that seek to structure teaching on a day-to-day basis (e.g., including lesson plans, resource links, teaching time stipulations, etc.). Consequently, a parsimonious framework can support the structuring of learning across a variety of diverse contexts and allow those closest to the context to deploy their expertise to make learning as effective as possible. Such a framework does not set out to specify the total experience for learners but focuses on essential concepts that form a foundation, which educators can elaborate on and supplement at a local level.

\section{A three-stage approach to curriculum framework development}

In this section we outline a three-stage approach to curriculum framework development (Figure 1). We call this the $C D C$ approach, as the three stages include consideration of: (a) context (principles and parameters); (b) descriptor generation; and (c) coherence establishment. This thinking informed our involvement in a joint-partnership project with UNICEF (the United Nations Children's Fund). UNICEF's mission is to advocate for the protection of children's rights, help meet their basic needs, and expand their opportunities to reach their full potential, and the agency was keen to explore the creation of a learning framework that could apply to a multiplicity of EiE contexts.

The brief from UNICEF to the research team in Cambridge stipulated that the framework should aim to assist the hardest-to-reach learners who may be least well served by current arrangements. The brief also stipulated that the framework needed to outline 


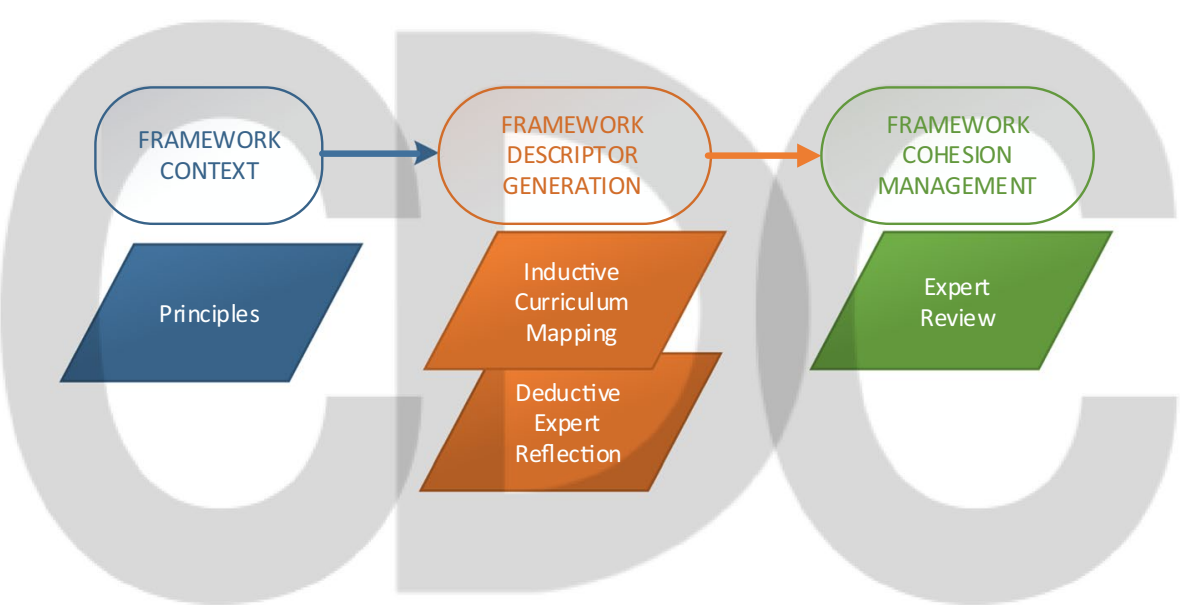

Figure 1 Our CDC model of curriculum framework development

learning sequences for Maths, Science, and Literacy and be aimed at learners around the ages of 5 to 14, as these were considered to be gaps in the current provision for displaced learners. In this paper we outline the process we developed for the Maths and Science components of the framework, as this was the earliest stage of the design process. We intended our framework to deal with the high-level sequencing of learning concepts that would then be developed into a locally relevant curriculum and into a set of learning activities at a local level. Although we set out the curriculum framework development model here, we are not yet in a position to review and evaluate it in practice, as the framework has not yet been implemented at the time of writing.

In the initial development of the curriculum framework, we needed to navigate through the uncertainties that characterize EiE contexts. At the outset we had many unanswered (and perhaps unanswerable) questions to work around. These included who would experience an enacted curriculum based on the framework; who would facilitate, teach, coordinate, and construct the enacted curriculum; what resources would be available; what learning spaces would be used; where the learners would be; and where they may be likely to move to (both geographically and as learners). To navigate around these many uncertainties, and to impose order on the development, we worked through a series of stages for each of the subjects in our framework. We outline these three stages in the next section.

\section{Stage 1 - Context: Principles and parameters}

The first stage of the framework development process was to establish a set of principles to guide the development. These design principles needed to reflect the needs of the context(s) in which the framework content was to be deployed. By having a set of principles for making decisions about the important structure and content of the learning framework, we could make sure we did not overlook the learning context in the development process. Although EiE is a challenging and inevitably diverse context, by working at the level of principles we could describe the context according to a broad set of assumptions and start to define the "ill-defined problem space". 
This first stage involved development team discussions around the assumptions that we believed should inform the framework. By attending to our most important priorities we were able to shape the emerging curriculum framework in relation to the demands of the project brief. Our team ultimately agreed on eight principles (Table 1), ordered according to their importance.

At the highest level of the hierarchy we placed the need for the framework to support learning progress, as supporting high-quality learning is one of the 17 Sustainable Development Goals adopted by all United Nations Member States in 2015 (United Nations Department of Public Information, 2019). Intrinsic to our model was a view that subject-based knowledge progressions would be applicable to all learners. There is very little empirical evidence around effective frameworks in EiE contexts, but there is acknowledgment that foundation skills are important to learning (UNHCR, 2016b) and that the vast majority of well-performing education systems structure their curricula by content (Ruddock et al., 2008). We also note that Literacy is commonly presented as the educational priority in EiE contexts (Oghenekohwo \& Frank-Oputu, 2017), whilst beyond EiE many recognize that Maths underpins the Sciences and other employment opportunities (Andrade-Arechiga et al., 2013; Smith, 2004).

Principle 2 reflected our ambition that the framework should support the ability of learners to move between education systems so as not to hinder their potential mobility and life chances. The third principle reflected our ambition that the framework should support efficient learning through ensuring that the most important elements of learning structured the sequence of the framework. We anticipated that by including a relatively parsimonious number of core content areas in the framework, we would allow room for important localized, pedagogic contextualization. This would help to attend to concerns that overburdened and decontextualized frameworks can lead to variances across different contexts as localized choice and prioritization takes place (Oates, 2011).

Principle 4 considered the nature of the learning content that we felt needed to be incorporated into the framework. Including content that was as context-agnostic as possible would facilitate the movement of learners between different education systems. This represented the ambition that the framework would be the basis for the temporary organization of education prior to learners moving into a non-emergency context.

Principles 5 and 6 reflected our concern that we could not let the potentially limited resource conditions of some EiE contexts determine the learning content. We were worried

Table 1 Key principles that informed our framework development

\begin{tabular}{ll}
\hline Framework design principle \\
\hline 1 & Needs to support progress in the subject area for all learners \\
2 & Needs to support potential reintegration of all learners \\
3 & Prioritizes depth over breadth. Ensures time is used to move learners forward with key building blocks \\
4 & Needs to be as context-agnostic as possible. Concepts and knowledge need to be abstract in nature, so \\
& that they can be applied in a variety of contexts \\
6 & Cannot rely on learning resource availability \\
7 & Cannot rely on specialist teacher knowledge or guidance. Requires clarity in language and terminology \\
8 & Should support social interaction \\
\hline
\end{tabular}


that by allowing the context to limit the content of the framework we would undermine the ambition of Principles 1 and 2 (that important learning should be available for all learners regardless of context). Principle 7 reflected our concern that the social and emotional development of learners needed to be acknowledged, with interaction supporting potential social integration. With respect to this framework principle we benefited from the expertise of the Department of Psychology at the University of Cambridge. The details of this particular research are beyond the scope of this article, but more information is available from Boyd-MacMillan and DeMarinis (2019).

Finally, we acknowledged in Principle 8 that assessment is an important tool for both encouraging learners to take control of their learning (through recognizing areas for further development) and for integration into other education systems through capturing evidence of a learner's progress in various subjects.

Taken together, the eight principles ensured that we considered the logical and efficient structuring of content in our emerging framework design. Just as importantly, the principles steered our decision-making around the nature of the content that the framework would structure. In the next section we outline how we built on our outlined principles to begin constructing our curriculum framework.

\section{Stage 2 - Descriptor generation}

Given the exploratory nature of the framework development, our approach to identifying the framework content drew on multiple perspectives. The integration of both inductive and deductive reasoning is an established approach for developing a broad understanding of a phenomenon (in this case, learning concept structures in different subject areas). Inductive reasoning involves using specific observations to build broader-level generalizations and theories, whilst deductive reasoning engages with established theories and generalized cases and relates these to specific cases. This integrated approach fits with a tradition in curriculum framework design, "[where] those responsible for setting educational goals may turn to tradition or evidence when seeking to revise curriculum and practice" (Jameson, 2016, p. 4).

For this development we wanted to integrate information from both inductive and deductive perspectives. For us, one form of evidence for gaining an inductive perspective was to draw on information from across educational systems. From these, we analyzed patterns of behaviors and outcomes to gain insight into how various systems have structured a subject. Information gathered from a deductive perspective engages with research outcomes and/or with experts who can use their experience and understanding of theory to make sense of the subject area. In a very general way, this process relies on the expert's careful consideration of the logic of the subject area to elicit the key areas of the domain, including consideration of its organizational features and interlinking concepts.

\section{An inductive approach: Curriculum mapping}

As part of an inductive approach for our framework development we wanted to draw on information about the structures of learning content from across different educational systems. The use of comparative data as a research evidence base for developing curriculum policy and practice reform is considered to be a generally useful approach (Burns $\&$ Schuller, 2007) since it is argued successful systems share common characteristics 
(Schmidt, 2004). This approach has informed curriculum development in England and beyond (Creese \& Isaacs, 2016; Oates, 2011; Ruddock et al., 2008).

Once we had decided to seek information from across different systems, we needed to choose a methodological approach for integrating such information. We adopted curriculum mapping, as it is a well-established method that has been used in a variety of contexts to represent the relationships within and between curricula (Elliott, 2014). The constructed representation then allows the main patterns across different curricula to be systematically gathered and related to each other. Mapping has a number of potential advantages. It can help to identify the most efficient ways of sequencing content in a curriculum framework, and it can also help to identify which types of content are highly valued in different systems.

In order to choose which education systems to draw information from, we also needed to determine a methodological approach. We wanted to consider how learning was organized (i.e., how the learning constructs were arranged and sequenced) in education systems where learners exhibited relatively high performance in our subjects of interest (i.e., Maths and Science). To do this we drew on outcomes that are commonly used to compare different educational systems. These outcomes are based on a variety of metrics such as the Trends in International Mathematics and Science Study (TIMSS), the Progress in International Reading Literacy Study (PIRLS) and the Programme for International Student Assessment (PISA) data.

For the Maths framework development, we specifically sought out comparisons where one system showed relatively high levels of learner attainment, as this offered some empirical evidence that the way that system organized the Maths curriculum was supporting learner development. This approach builds on the tradition from other researchers who have reviewed comparative method results as part of curriculum design, claiming that High Performing Jurisdictions reflect "the best collective wisdom we have about how children learn and what they should know" (Department for Education, 2011, p. 6). Our Maths analysis identified nine jurisdictions of interest: Australia (Victoria), Canada (Alberta), China (Shanghai), Finland, Hong Kong, Japan, United States (Massachusetts), New Zealand, and Singapore.

Studying how different systems organized their curricula also supplied insight into how the key elements of a subject domain were defined at a social level (e.g., how a subject area was categorically divided into specific domains). This categorization of knowledge is important since one ambition of a curriculum framework is that it conveys the generic characteristics of knowledge that form the basis of transfer between systems. For example, many of the sampled High Performing Jurisdiction curricula organized Maths into "Number", "Measurement", "Geometry", and "Statistics" (Cambridge Assessment, 2020, p. 25). If a generic framework includes universal features, it can facilitate the movement of learners across the boundaries between different jurisdictions.

We also wanted to ensure our educational system comparison took into consideration some contextual criteria. We mapped the curricula from systems that had relatively high levels of learner populations that have been identified as being of concern to UNHCR. Information from these curricula could tell us something about learning content that was considered important in such conditions, and this information could add power to the transfer potential of the framework components. This approach was particularly important for the Science framework development, as some of the concepts in that area were more likely to relate to the context of learning, compared with Maths concepts. To do this we selected a group of curricula that were included in UNHCR's Forced Displacement Global Trends report (UNHCR, 2018). This report identified nine jurisdictions with relatively high 
levels of learners who were refugees, asylum seekers, internally displaced people (IDP) of concern, returned refugees, returned IDPs, or stateless people: Bangladesh, Chile, Cote D'Ivoire, Pakistan, Lebanon, Myanmar, Turkey, South Sudan, and Thailand. This approach foregrounded the importance of specific concepts; for example, the fundamental idea that "living things interact with one another and the physical environment" highlights how understanding micro-organisms and pathogens links to health, hygiene, and preventing disease transmission (Cambridge Assessment, 2020, p. 87).

\section{A deductive approach: Expert reflection and theory}

In addition to the empirical information we gathered through the inductive approach about how other successful systems sequence their learning frameworks, we felt it was important to glean information from a deductive perspective. To consider these learning concept sequences, we sought expert and theoretical perspectives. These perspectives, grounded in experience and research literature, enabled us to construct a rationale around the learning sequences, and in effect help to validate them.

Using the outcomes from the mapping exercise as a resource, we encouraged subject experts to reflect on the structure and content of the subject domain. This process therefore represented an interplay between inductive and deductive perspectives, as the curriculum and subject experts related their experience and theory to the messages gleaned through the curriculum mapping exercises.

To structure this interplay, we set up a number of expert development meetings centered around the question, "What knowledge would learners need to know in order to build up their understanding of a given domain?" This then led to a series of additional questions, which experts answered with recommendations:

- Which subdomains should be used? Example response: we introduced an "algebra working and thinking" Maths subdomain, as our review suggested that this discrete skill helps learners to explore the structure of Mathematics patterns and functions.

- What is the relationship between subdomains? E.g., in Maths we wanted to address expert concerns around the ways that "Data Handling" is structured in some curriculum models. Avoiding an overemphasis on content (forms of data presentation), we wanted to focus on how learners work with data (interpretation, comparison, or prediction).

- Which concepts overlap, leading to decisions to merge? E.g., our Maths review suggested that "Multiplication" and "Division" should be taught together as related concepts. The ideas of "Sharing" and "Partitioning" also link to "Fractions", supporting the decision to merge "Fractions" into the "Number" subdomain.

- Which concepts are not necessary, leading to decisions to remove? E.g., we decided to remove references to money from the Maths framework as this could be culturally specific.

- Which concepts are central, leading to decisions to retain? E.g., our analysis led to the removal of "Pythagoras" from being embedded in the "Shape" concept in Maths, and giving it its own set of discrete descriptors.

- Is the order of sequence supported by the experts?

The emerging curriculum framework revision meetings then focused on: 
- Defining the key/salient concepts (following the removal of concepts during the previous expert meetings). E.g., for the "Number" Maths subdomain we identified the key concepts as "Understanding the Number System", "Understanding Subitizing/Estimating”, "Understanding Place Value”, "Understanding Adding and Subtracting”, "Understanding Multiplication and Division".

- Identifying the subject domain in which each key/salient concept should reside. E.g., for the Maths framework we defined these as "Number and Fractions", "Geometry", "Measure”, "Algebra Working and Thinking”, "Data Handling and Risk”.

- Reviewing the sequences inherent to each key/salient concept.

Although adhering to the same design principles, this review and refinement process differed across domains. For example, the discussions at each meeting were always informed by additional literature that the experts identified as important.

Given the uncertainties around EiE contexts, we recognized the importance of integrating both inductive and deductive approaches for our curriculum framework development. This dual approach had similarities to established approaches that interlink empirical observation and research as a way of optimizing curriculum design (e.g., Smith et al., 2006). By structuring curriculum design as an iterative process involving a dual approach, it could also be possible to mitigate some of the problems that might occur if designers based assumptions on the empirical route alone. Our process sets out to establish, through both empirical evidence and theoretical reasoning, a hierarchy of conceptual understandings that proceed over the course of learning a subject (Lobato \& Walters, 2017). It has been noted that high performing educational jurisdictions incorporate such a dual process (Valverde \& Schmidt, 1998).

\section{Defining the framework content sequences}

The next stage of the process was to use the content that was generated, reviewed, and refined through expert reflection to create a series of content sequences that would form the substantive basis of the curriculum framework. In order to do this, we needed to establish the parameters for the framework descriptor generation.

One such parameter was already established by our decision that Maths and Science would be the subjects and domains forming the content basis of the framework. It was also important to determine the number of levels into which to organize these descriptors. The choice of levels is an important component of the coherence of the framework (see section below for more on this) and can be determined according to several considerations. The number of sequencing levels may be based on the natural flow of change in the development of concepts, which could vary across the different concepts in a framework, or on the level of granularity in which the descriptors were described. Alternatively, the number of levels in the framework could be based on time intervals, such as years of human development or schooling expectations. We had a notional focus on learners from the earlier stages of formal education through the early teenage years, so we decided to segment our framework into nine levels, roughly corresponding to years of education. This sequence ordering could then be used by local curriculum developers, who would have flexibility as to how they wished to apply these sequences across age or learning levels in their specific context.

Descriptor granularity was also important to consider. The parsimonious principle we defined at the outset of our framework development meant that we anticipated the descriptors would capture enough detail of the concepts that curriculum and learning material developers could make sense of them. 
However, there would always need to be an additional stage of development for transferring the descriptors into the language of the learning context. Once the descriptors were developed into sequences across a number of subjects and levels, we needed to consider the final stage of the development process: the interplay of these descriptors across the different parts of the framework. We outline this stage in the next section.

\section{Stage 3 - Coherence establishment}

The final stage of development represents the shift from a focus on the individual subject components of the curriculum framework to a focus on the overall framework, encompassing all levels and subjects. This shift involved two related elements: establishing coherence across the content within each subject (intra-subject), and establishing coherence across the content of the different subjects within the framework (inter-subject). Coherence is a concept that is used to describe the contingent relations across the contents of the framework, and is considered to be a key element that contributes to the impact of curriculum frameworks (Schmidt \& Prawat, 2006).

We theorized coherence around the notion of establishing common ground, since the experts needed to reach a consensus about where to place concepts in the framework. The common ground notion holds that all collective actions are made possible where participants share a common underpinning knowledge and understanding, on which they can build a joint vision (Littleton \& Mercer, 2013).

The establishment of common ground allows experts to identify the links between related concepts in different places across the framework. For example, it was important to locate foundational concepts at earlier levels in one subject prior to them being encountered in another. In Maths Level 4 the learners encounter a simpler concept of Mass ("Develop and use the standard unit of kilogram [discussion of weight vs. mass to follow in science]"), which then supports their more complex conceptual encounter with it at Science Level 8 ("Every element and every compound has unique properties including density [the amount of mass in a given volume]"). To help establish common ground between subject experts, it would be useful at the project outset to state a view of the intended goals. Thus, as a precursor to the descriptor generation meetings, we introduced the subject experts to the key principles that underpinned the framework development process. These meetings, where we elaborated the project principles and parameters, allowed us to develop a form of background common knowledge for all of the participating developers, and this formed the basis for coherent development as the project progressed.

After generating the descriptors in each subject subdomain, we brought experts together to consider the interconnection of the concepts across the framework. Using a specified number of levels at the outset of the framework development process facilitated this interconnection stage. The work of interconnecting the concepts in the descriptors required a discursive process to establish which concepts connected (both within a subject and across different subjects), whether the related concepts resided in the same framework level, and whether any contingencies (i.e., preceding concepts important for later conceptual understanding) were placed in the correct sequence. These interactions represented a form of dynamic common knowledge building as the experts came to relate concepts from the different domains to those in their own-for example, mathematicians and scientists coming to shared agreement around how the concept of Mass should be described in overlapping parts of the framework. However, coherence building is an ongoing process, and curriculum developers must continue to consider these issues as they use the framework to construct curricula and develop learning materials. 


\section{Discussion and implications}

In this paper we have outlined how EiE can use a principled approach to support the decision-making of developers working to provide educational solutions. We also need to be explicit at this stage that we are not in a position to evaluate the implementation of the framework, as it is still in the process of being rolled out.

Our intention in setting out the principles and theories that underpinned our approach to developing a curriculum framework, albeit set within a specific design brief context, is to encourage critical reflection around the process of designing education provision for EiE contexts. We hope our 3-stage $C D C$ development approach will help other education developers to streamline decision-making and contribute to the efficient division of labor where developers work in inter-agency partnership working arrangements. This is a challenge that others have noted (Devitt \& Borodzicz, 2008), and we acknowledge we need to further consider whether our framework attains its stated aims. At the time of writing the framework has not been piloted.

The development of learning initiatives in EiE contexts is analogous to working in an ill-defined problem space. Developers can lack assuredness in their design outcomes due to the social messiness of the context (Joseph, 2004). We argue that a parsimonious conceptualization of a curriculum framework, in line with Seifert (2019), can be helpful for structuring a response in such challenging environments. This is because the design of such frameworks involves issues such as balancing appropriate levels of structure and deciding the degree to which flexible action is permitted. These issues point to how centralization and localization interplay when we establish and use a framework. On the one hand, curriculum frameworks can possess a generic capacity to coordinate actions around high-level learning concepts and sequences. On the other hand, they can allow important flexibility for localized decision-making, allowing specific features to be included in the learning experiences for particular learners in different contexts.

There is relatively little empirical evidence that curriculum frameworks have been used in emergency education. Given this lack of evidence, we take existing understanding around why frameworks can be effective and relate it to EiE contexts. Learning in EiE contexts is complex since the mobility of individual learners (and teachers) means they may encounter multiple and conflicting curricula and/or modes of assessment within a defined geographical area (Dryden-Peterson, 2015). Having a learning framework that incorporates some of the key conceptual elements of other national systems can support learner reengagement in any particular system. Evidence also suggests that learning facilitators can more easily develop learning plans and map available resources to these plans when curriculum frameworks sequence concepts that align with each other (Gunckel et al., 2018). Such coherence is also a feature of successful learning systems (Schmidt \& Prawat, 2006), where it is common to structure curricula by content (Ruddock et al., 2008).

When thinking about which concepts to include in a framework, we look to evidence from EiE contexts that suggests foundational learning skills are important (UNHCR, 2016b). Literacy is a ubiquitous educational priority in EiE contexts, helping to maximize life opportunities and decrease vulnerability (Oghenekohwo \& Frank-Oputu, 2017). Moreover, Maths is a crucial area of learning as it underpins the Sciences and helps to prepare learners for most forms of employment (Smith, 2004). Science is a form of specialized knowledge providing insight into the natural world, empowering learners to understand how their localized experience links with other contexts beyond their immediate experience (Young \& Muller, 2013). 
A development team should also be able to agree on the compromises they may need to make in the framework construction process. We suggest that having a set of principles can help developers through this tricky process. Our framework development approach is rationalized around three principle-based stages, which we feel have relevance beyond our own particular research project. The first stage includes consideration of the needs of the context(s) in which the framework content is to be deployed.

A general concern about frameworks is that the language of the learning descriptors can become misinterpreted when applied to a curriculum. This is of particular concern if a framework is translated into languages other than the language of first development. One solution is to impose more centralized control on the application process through providing terminology lists that support the enactment of the framework. These lists can inform the development of the curriculum documents and learning materials that are based on the framework.

At the second development stage we outlined how we integrated multiple perspectives to identify potential framework content that conformed to the knowledge needs we identified in the first stage. Our methodology allowed the interplay of information from across a variety of education systems, expert perspectives, and theory. This method led us to identify a sequence of concepts that structured the framework across several subject domains.

The final development stage involved establishing coherence across the framework. This stage involved a shift from a focus on the individual subject components of the curriculum framework to a focus on the complete framework itself. To achieve this coherence, we developed a discursive approach that allowed expert reviewers to establish common ground which included both background and dynamic elements.

In conceptualizing the staged nature of the framework development process, we have also become aware of some of the associated challenges. Although we provide a generic overview of the stages that we believe developers will need to consider, we also do not want to under-represent the amount of decision-making and variability that might arise as developers progress through these stages.

Important decisions must be considered when choosing an evidence gathering process to inform the framework development. Developers can use a variety of methods to gain insight into comparative systems; however, they need to make explicit their rationale for method choice and provide evidence that they have critiqued the strengths and limitations of each selected method.

We also feel there is further scope to explore the methods that might be used for the final stage of the framework and curriculum development process. There is a need to further elaborate on the methods that can be used to build coherence within and across framework subjects. We have not found a literature that deals with this issue in specific terms, but we are aware that this process needs to be a discursive one that allows experts to establish connections between shared, overlapping concepts. According to our conceptualization, these processes will need to allow participating subject experts to build dynamic common knowledge as they come to relate concepts from the different domains to those in their own.

\section{References}

Andrade-Arechiga, M., Lopez, G., \& Pulido, J. R. G. (2013). Mathematics education and information technologies in emerging economies. Creative Education, 4(10), 40-47. https://doi.org/10.4236/ce.2013. $410 \mathrm{~A} 007$. 
Australian Government (2018). Through growth to achievement: Report of the review to achieve educational excellence in Australian schools. Department of Education and Training. https://www.dese.gov.au/quali ty-schools-package/resources/through-growth-achievement-report-review-achieve-educational-excellenceaustralian-schools

Boyd-MacMillan, E., \& DeMarinis, V. (2019). Learning passport: Curriculum framework (IC-ADAPT SEL high level programme design). Cambridge University Press \& Cambridge Assessment.

Burns, T., \& Schuller, T. (2007). The evidence agenda. In T. Burns \& T. Schuller (Eds.), Evidence in education: Linking research and policy (pp. 15-32). OECD/CERI. http://www.oecd.org/education/ceri/47435459.pdf

Cambridge Assessment (2020). The learning passport: Curriculum framework (maths, science, literacy). Cambridge Assessment. https://www.cambridge.org/files/7615/8465/3386/The_Curriculum_FrameworkMaths_Science_Literacy.pdf

Çelik, Ç., \& İçduygu, A. (2019). Schools and refugee children: The case of Syrians in Turkey. International Migration, 57(2), 253-267. https://doi.org/10.1111/imig.12488.

Creese, B., \& Isaacs, T. (2016). International instructional systems: How England measures up. The Curriculum Journal, 27(1), 151-165. https://doi.org/10.1080/09585176.2015.1131171.

Department for Education (2011). Framework for the National Curriculum: A report by the expert panel for the national curriculum review. Department for Education. https://www.bl.uk/collection-items/framework-forthe-national-curriculum-a-report-by-the-expert-panel-for-the-national-curriculum-review

Devitt, K. R., \& Borodzicz, E. P. (2008). Interwoven leadership: The missing link in multi-agency major incident response. Journal of Contingencies and Crisis Management, 16(4), 208-216.

Dhillon, N., Dyer, P., \& Yousef, T. (2009). Generation in waiting: An overview of school to work and family formation transitions. In N. Dhillon \& T. Yousef (Eds.), Generation in waiting: The unfulfilled promise of young people in the Middle East (pp. 11-38). Brookings Institution Press.

Dryden-Peterson, S. (2015). Refugee education in countries of first asylum: Breaking open the black box of preresettlement experiences. Theory and Research in Education. https://doi.org/10.1177/1477878515622703.

Education Co-Sponsorship Alliance (2019). Global framework for refugee education. UNHCR. https://www. unhcr.org/5dd50ce47.pdf

Elliott, G. (2014). Method in our madness? The advantages and limitations of mapping other jurisdictions' educational policy and practice. Research Matters: A Cambridge Assessment Publication, 17, 24-29.

Green, D. (2013, September 10). If high staff turnover is unavoidable, how should we redesign aid work to cope? From Poverty to Power. https://oxfamblogs.org/fp2p/if-high-staff-turnover-is-unavoidable-howshould-we-redesign-aid-work-to-cope/

Gunckel, K. L., Covitt, B. A., \& Salinas, I. (2018). Learning progressions as tools for supporting teacher content knowledge and pedagogical content knowledge about water in environmental systems. Journal of Research in Science Teaching, 55(9), 1339-1362. https://doi.org/10.1002/tea.21454.

Jameson, E. (2016). Roles and limits of curriculum frameworks in mathematics education. Cambridge Mathematics. https://www.cambridgemaths.org/Images/research-2-roles-and-limits-full.pdf

Joseph, D. (2004). The practice of design-based research: Uncovering the interplay between design, research, and the real-world context. Educational Psychologist, 39(4), 235-242. https://doi.org/10.1207/s15326985e p3904_5.

Littleton, K., \& Mercer, N. (2013). Interthinking: Putting talk to work. Routledge.

Lobato, J., \& Walters, C. D. (2017). A taxonomy of approaches to learning trajectories and progressions. In J. Cai (Ed.), Compendium for research in mathematics education (pp. 74-101). National Council of Teachers of Mathematics Inc.

Mendenhall, M., Skinner, M., Collas, S., \& French, S. (2018). Expanding teacher support through mobile mentoring in Kakuma Refugee Camp: Benefits and challenges. Current Issues in Comparative Education, 20(2), 9-23.

Oates, T. (2011). Could do better: Using international comparisons to refine the National Curriculum in England. The Curriculum Journal, 22(2), 121-150. https://doi.org/10.1080/09585176.2011.578908.

OECD [Organisation for Economic Co-operation and Development] (2018). OECD Learning Framework 2030. OECD. https://www.oecd.org/education/2030/E2030\%20Position\%20Paper\%20(05.04.2018).pdf

Oghenekohwo, J. E., \& Frank-Oputu, E. A. (2017). Literacy education and sustainable development in developing societies. International Journal of Education and Literacy Studies, 5(2), 126. https://doi.org/10.7575/ aiac.ijels.v.5n.2p.126.

Ruddock, G., Sainsbury, M., Clausen-May, T., Vappula, H., Mason, K., Patterson, E., ... Rees, F. (2008). Comparison of the English Core Primary Curriculum to those of other high performing countries (No. DCSFRW048). NFER. https://www.nfer.ac.uk/publications/BPC01/

Schmidt, W. H. (2004). A vision for mathematics. Educational Leadership, 61(5), 6.

Schmidt, W. H., \& Prawat, R. S. (2006). Curriculum coherence and national control of education: Issue or nonissue? Journal of Curriculum Studies, 38(6), 641-658. https://doi.org/10.1080/00220270600682804.

Seifert, K. (2019). Educational psychology. The Open University of Hong Kong. 
Smith, A. (2004). Making mathematics count: The report of Professor Adrian Smith's inquiry into post-14 mathematics education. DfES. https://dera.ioe.ac.uk/4873/1/MathsInquiryFinalReport.pdf

Smith, C. L., Wiser, M., Anderson, C. W., \& Krajcik, J. (2006). Implications of research on children's learning for standards and assessment: A proposed learning progression for matter and the atomic-molecular theory. Measurement: Interdisciplinary Research and Perspectives, 4(1-2), 1-98. https://doi.org/10.1080/ 15366367.2006.9678570.

UN [United Nations] (2018). Report of the United Nations High Commissioner for refugees, Part II: Global compact on refugees. United Nations. https://www.unhcr.org/gcr/GCR_English.pdf

UN (2019). Global compact for safe, orderly and regular migration. United Nations. https://documents-dds-ny. un.org/doc/UNDOC/GEN/N18/451/99/PDF/N1845199.pdf?OpenElement

UNHCR (2016a). Left behind: Refugee education in crisis. UNHCR. https://www.unhcr.org/left-behind/

UNHCR (2016b). Missing out: Refugee education in crisis. UNHCR. http://www.unhcr.org/publications/educa tion/57d9d01d0/missing-refugee-education-crisis

UNHCR (2018). UNHCR global trends: Forced displacement in 2017. UNHCR. https://www.unhcr.org/globa ltrends2017/

United Nations Department of Public Information (2019). Sustainable Development Goals: SDG knowledge platform. https://sustainabledevelopment.un.org/sdgs

Valverde, G. A., \& Schmidt, W. H. (1998). Refocusing U.S. math and science education. Issues in Science and Technology, 14(2), 60-66.

Waters, C., Jackson, J., Adams, R., \& Schwantner, U. (2018, May 29). The role of learning progressions in global scales. Brookings Institution. https://www.brookings.edu/blog/education-plus-development/2018/ 05/29/the-role-of-learning-progressions-in-global-scales/

Young, M., \& Muller, J. (2013). On the powers of powerful knowledge. Review of Education, 1(3), 229-250. https://doi.org/10.1002/rev3.3017.

Publisher's Note Springer Nature remains neutral with regard to jurisdictional claims in published maps and institutional affiliations.

Martin Johnson is a senior researcher at Cambridge University Press \& Assessment's Research and Development Division. He is a Fellow of the International Society for Design and Development in Education, and an Executive Member of the British Association for International and Comparative Education. The focus of much of his work is on the interaction between assessment, learning, and curriculum issues, often with an international focus. Projects have ranged across academic and vocationally related contexts and investigated assessment issues in diverse sectors (e.g., primary through to post-compulsory education). His general research interest is on how to better understand assessment as enacted practice. This has involved using assorted qualitative research methods to gather the perspectives of those involved with, or affected by, assessment.

Sinéad Fitzsimons was formerly a researcher at Cambridge Assessment's Research and Development Division and is now a curriculum developer and teacher at the International School of Brussels. She is also a researcher at the European Association of Citizenship and History Education (EUROCLIO). Sinéad has worked on many international curriculum development projects, especially in post-conflict and divided societies. This has involved curriculum and resource development, monitoring and evaluation, and teacher training. Her PhD research, completed at Queen's University Belfast, focused on the influence of curriculum on how young people view and develop their sense of identity. Currently, Sinéad is developing a K-12 Social Studies curriculum to be used in International Schools.

Victoria Coleman was formerly a researcher at Cambridge Assessment's Research and Development Division. Victoria's background is in Psychology and Education, she has a B.Sc. in Psychology from the University of Bath, and an M.Phil. in Education (Psychology and Education) from the University of Cambridge focusing on Developmental Coordination Disorder (DCD). As a researcher at Cambridge Assessment her work related to curriculum development and review, decolonizing the curriculum, education in emergencies, assessment literacy, and teacher experiences during Covid-19. She is currently undertaking a $\mathrm{PhD}$ in Psychology at the University of Bath focusing on understanding mental health in neurodevelopmental conditions. 